\title{
Insulin attenuates scopolamine-induced memory deficits
}

\author{
CLAUDE MESSIER \\ University of Ottawa, Ottawa, Ontario, Canada \\ and \\ CLAUDE DESTRADE \\ University of Bordeaux I, Talence, France
}

\begin{abstract}
Most of the agents that attenuate scopolamine-induced amnesia can also improve memory when injected alone. We report here that insulin can attenuate scopolamine-induced amnesia even though insulin per se has little memory-improving action. Male Balb/c mice were trained in an appetitive barpressing task. Immediately after the mice had completed 15 trials, scopolamine hydrochloride was injected $(0.1,0.2,0.3,0.6,1.0 \mathrm{mg} / \mathrm{kg}$ i.p.) in conjunction with either saline or insulin $(0.8 \mathrm{IU} / \mathrm{kg}$, subcutaneously). The animals' retention of the training was tested the next day. The 0.6- and $1.0-\mathrm{mg} / \mathrm{kg}$ doses of scopolamine (but not the lower doses) produced an amnesia for the barpressing task training. This amnesia was significantly reduced by an insulin injection given at the same time as the scopolamine injection. However, the injection of insulin alone had no effect on memory processes. These results show that insulin can protect from scopolamine amnesia. Possibly, insulin modulates scopolamine-induced amnesia directly through an action on insulin receptors in the brain.
\end{abstract}

There is now clear evidence that posttraining injections of glucose can facilitate the retention of various types of appetitive and aversive training both in rats (Gold, Vogt, \& Hall, 1986; Long, Davis, Garofalo, Spangler, \& Ingram, 1992; Messier \& White, 1984, 1987; Packard \& White, 1990; Rodriguez, Van Ausdle, Dhanens, \& Mondragon, 1993) and in mice (Means \& Fernandez, 1992; Messier \& Destrade, 1988; Stone, Rudd, \& Gold, 1990). Glucose can also facilitate learning and memory processes in aged humans (Gold, 1991; Gonder-Frederick et al., 1987; Hall, Gonder-Frederick, Chewning, Silveira, \& Gold, 1989; Manning, Parsons, \& Gold, 1992; Parsons \& Gold, 1992a) and in patients suffering from mild Alzheimer's disease (Craft, Zallen, \& Baker, 1992).

The mechanisms underlying the memory-improving action of glucose remain unknown. Several hypotheses have been proposed, including one that suggests a peripheral and a central locus of action of glucose (Gold, 1991; White, 1991). However, the demonstration that posttraining intracerebroventricular injections of glucose improved retention of a passive avoidance training experience in rats (Lee, Graham, \& Gold, 1988) suggested that glucose could act directly on a central nervous system (CNS) substrate to improve memory.

This research was supported by the CNRS (URA 339) and the University of Bordeaux I. C.M. was supported by a fellowship from the Human Frontier Science Program. We would also like to acknowledge Jamila Sif for technical help and T. Durkin for helpful comments on this manuscript. Address correspondence to C. Messier, School of Psychology, University of Ottawa, Vanier: Room 215, Ottawa, Ontario, K1N 6N5, Canada.
In other studies, the interaction between glucose administration and the effect of scopolamine has been examined. Scopolamine is a well-known amnestic agent that appears to produce amnesia by its blocking action on muscarinic cholinergic receptors in the brain (Flood \& Cherkin, 1986; Quartermain \& Leo, 1988; Rush, 1988). Glucose injections attenuated the increases in locomotion (Stone, Cottrill, \& Gold, 1987) and the amnesia (Messier, Durkin, Mrabet, \& Destrade, 1990; Stone, Croul, \& Gold, 1988) produced by peripheral scopolamine injections. An additional experiment showed that the deficits in spontaneous alternation performance produced by peripheral scopolamine injections could be attenuated by an injection of glucose in the lateral ventricle of the brain (Parsons \& Gold, 1992b).

Taken together, these studies suggest that one of the mechanisms by which glucose could produce its facilitative effect on memory is an action on central cholinergic function. This possibility is supported by a number of experiments described below in which the relationship between glucose availability and acetylcholine synthesis in the brain was examined.

Under normal conditions, glucose is the main source of the acetyl groups for acetyl coenzyme A (acetyl-coA), which is one of the two precursors used to synthesize acetylcholine (ACh) in the mammalian brain (Quastel, 1978; Tucek, 1983, 1985). When glucose availability is reduced by the injections of large doses of insulin, a reduction of ACh turnover rate is observed, which is proportional to the decrease in brain glucose levels (Gibson \& Blass, 1976; Gibson, Jope, \& Blass, 1975). Brain ACh levels are reduced in rats after a $24-h$ fast and restored 
to prefasting levels either by the combined administration of choline and glucose or by refeeding. In continuously fed animals, glucose had no such effect on ACh levels (Kuntscherova, 1972). These results suggest that one condition under which exogenously administered glucose may increase brain ACh levels is when glucose availability to the brain is decreased, and thus, presumably, under conditions of reduced levels of acetyl-coA.

In other experiments, the effect of glucose on ACh synthesis when ACh stores are being depleted has been examined. The peripheral injection of glucose attenuated the atropine-induced decrease of $\mathrm{ACh}$ content in the caudate nucleus, whereas glucose alone had no effect on ACh content in untreated (no atropine) animals (Tucek, 1983; Tucek, Ricny, \& Dolezal, 1982). In another experiment, glucose was shown to attenuate the striatal acetylcholine depletion produced by a peripheral injection of the muscarinic antagonist quinuclidinyl benzilate (Ricny, Tucek, \& Novakova, 1992).

We have previously shown that a subcutaneous injection of $3 \mathrm{~g} / \mathrm{kg}$ glucose given in mice in combination with an intraperitoneal (i.p.) injection of scopolamine $(1 \mathrm{mg} / \mathrm{kg}$ ) attenuated the scopolamine-induced increase in highaffinity choline uptake in the hippocampus as compared with saline-injected mice (Messier et al., 1990). This result was confirmed in an experiment that compared the microdialysate concentrations of acetylcholine from the hippocampus of fasted rats receiving an i.p. injection of scopolamine $(1 \mathrm{mg} / \mathrm{kg})$ with those of rats receiving a combined injection of scopolamine and glucose $(2 \mathrm{~g} / \mathrm{kg})$. Scopolamine injection resulted in a 10 - to 20 -fold increase in hippocampal ACh overflow; the combined injection of glucose with scopolamine resulted in a further $20 \%$ increase of ACh release during the 30-min period that followed the injections (Durkin, Messier, Boer, \& Westerink, 1992).

Taken together, these results suggest that when there is a high demand for $\mathrm{ACh}$, increased glucose availability facilitates $\mathrm{ACh}$ resynthesis. This facilitation may depend on an increase of the production and availability of acetyl-coA.

This interaction between glucose and acetylcholine synthesis could represent the basis for some of its action on memory, because forebrain cholinergic mechanisms, particularly those of the septo-hippocampal projection system, appear to play an important role in learning and memory processes (Bartus, Dean, Beer, \& Lippa, 1982; Brito, Davis, Stopp, \& Stanton, 1983; Durkin, 1989; Olton, Wible, \& Shapiro, 1986).

Several experiments have shown that shortly after learning a new task, the septo-hippocampal system of rodents appears to be activated, as measured by changes in choline acetyltransferase activity (Jaffard, Galey, Micheau, \& Durkin, 1985), a decrease in intracellular ACh levels (Matthies, Rauca, \& Liebmann, 1974), and an increase of sodium-dependent high-affinity choline uptake in the hippocampus (Burgel \& Rommelspacher, 1978; Raaij- makers, 1982; Rauca, Kammerer, \& Matthies, 1980; Toumane, Durkin, Marighetto, Galey, \& Jaffard, 1988; Toumane, Durkin, Marighetto, \& Jaffard, 1989). In one experiment, we showed that when glucose was administered shortly after training in a new task, it produced an attenuation of the test-induced activation of sodiumdependent high-affinity choline uptake in the hippocampus normally observed in those conditions. These results provided additional indirect evidence of a facilitation of ACh synthesis by exogenous glucose under conditions of increased ACh neuronal activity (Messier et al., 1990).

In summary, the interaction between glucose, scopolamine-induced changes in ACh function, and scopolamine-induced amnesia are generally in agreement with the hypothesis that the memory-improving action of glucose is mediated, at least in part, through an action on brain ACh function.

To further test this hypothesis, we examined the effect of insulin injections, which lower blood glucose, on scopolamine-induced amnesia. On the basis of the data presented above, we predicted that insulin would potentiate the amnestic effects of scopolamine via a reduction of the availability of acetyl-coA.

\section{METHOD}

\section{Subjects}

The subjects were 12- to 16-week-old male Balb/c mice (IFFACREDO, Lyon, France). They were housed individually in a temperature-controlled room on a 12:12-h light:dark cycle with adlib water and food, except as described in the procedure.

\section{Materials}

The operant test cage $(12.5 \times 13.5 \times 18.5 \mathrm{~cm})$ was made of translucent Plexiglas with a grid floor (Destrade, Soumireu-Mourat, \& Cardo, 1973). A metal bar and a food cup extended from one wall and were separated by a 5-cm-long partition so that, after a barpress, a mouse had to go around the partition to reach the food cup. The test cage controls were programmed for continuous reinforcement (CRF 1). A reinforced trial was defined as a barpress followed within $30 \mathrm{sec}$ by the consumption of a small $(5 \mathrm{mg})$ starshaped noodle made of durum wheat (Panzani).

Saline injections consisted of a sterile $0.9 \%(w / v)$ solution of sodium chloride; insulin injections consisted of $0.8 \mathrm{IU}$ of bovine insulin (Sigma) in $10 \mathrm{ml}$ of normal saline. The dose of insulin $(0.8$ $\mathrm{IU} / \mathrm{kg}$ ) was chosen so that glucose levels would be reduced significantly (from about $138.4 \pm 8.63 \mathrm{mg} / \mathrm{dl}$ in saline-injected animals to about $86.25 \pm 8.82 \mathrm{mg} / \mathrm{dl}$ in insulin-injected mice), but no adverse behavioral effect could be observed. In preliminary experiments, a dose of $1.0 \mathrm{IU} / \mathrm{kg}$ was shown to produce insulin-related coma in about $50 \%$ of the animals tested under the same conditions of food deprivation; the dose used in the present experiment did not produce any observable debilitating effects. Scopolamine hydrochloride (Sigma) was dissolved in normal saline to yield final solutions of $0.01,0.02,0.03,0.06$, and $0.1 \mathrm{mg} / \mathrm{ml}$.

\section{Procedure}

The animals were first placed into individual cages with food and water freely available. They were handled and weighed every 2 days for 1 week. At the end of this week, food was removed from the cages. During the next 4 days, the food ration was adjusted individually so that by the fifth day, all the animals had reached about 
$83 \%-85 \%$ of their ad-lib weights. The animals were given a few noodle reinforcers every day so that they would readily consume the reinforcers on the training day.

On the fifth day, all the animals were given 15 reinforced training trials. After training, they were returned to their cages and received immediate posttraining injections of saline $(n=7)$, insulin $(n=9)$, a combination of saline and various doses of scopolamine $(0.1, n=15 ; 0.2, n=13 ; 0.3, n=13 ; 0.6, n=9$; or $1.0 \mathrm{mg} / \mathrm{kg}, n=15)$, or a combination of insulin $(0.8 \mathrm{IU} / \mathrm{kg})$ and various doses of scopolamine $(0.1, n=13 ; 0.2, n=15 ; 0.3, n=$ $10 ; 0.6, n=9$; or $1.0 \mathrm{mg} / \mathrm{kg}, n=10$ ).

Two hours after the end of training, each animal received a food ration that was adjusted so that its weight the next day would be about $83 \%-85 \%$ of its ad-lib weight.

Twenty-four hours after the end of training, each animal was placed into the test chamber and given a 20 -min retention test under a continuous reinforcement schedule. Retention of the barpress training was measured by the number of reinforced responses made during the 20 -min period. Data analysis was carried out by using analysis of variance followed by a simple main effects analysis.

\section{RESULTS}

To assess the performance of the various groups during the initial training, we compared the time taken to complete the 15 reinforced responses. There was no overall difference between the time taken by the groups that had received scopolamine and saline or the groups that had received scopolamine with insulin $[F(1,128)=0.014$, n.s.], indicating that the animals' performance during training was comparable. No differences were found between the level of deprivation of the various groups before either the training session or the retention session.

The analysis of the results of the 20-min retention test (presented in Figure 1) showed that there was an overall effect of scopolamine $[F(1,128)=10.1, p<.0001]$, but

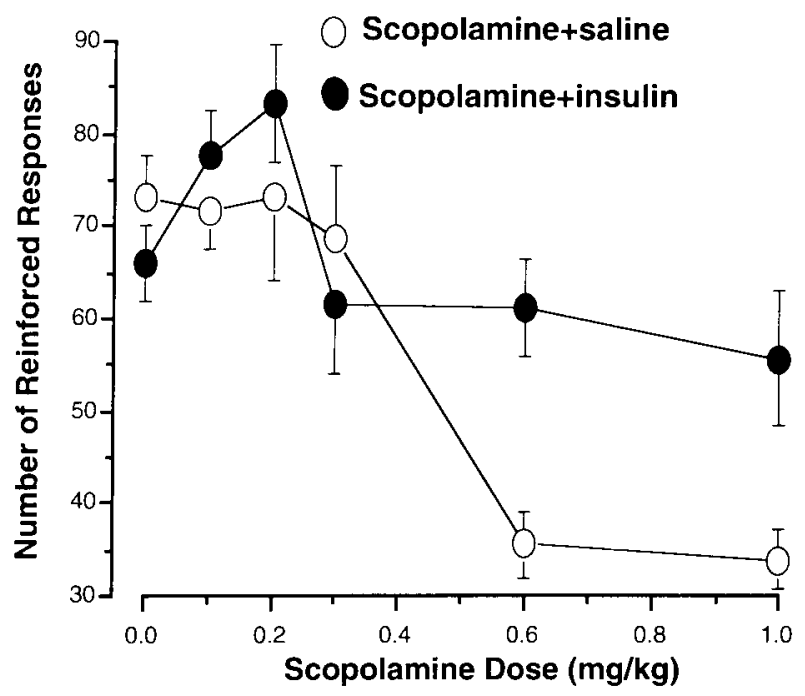

Figure 1. Number of reinforced responses $(M \pm S E M)$ made during the 20 -min retention test, $24 \mathrm{~h}$ after the animals had received saline, insulin $(0.8 \mathrm{IU} / \mathrm{kg})$, a combination of saline and various doses of scopolamine, or a combination of insulin and various doses of scopolamine. no significant effect of insulin $[F(1,128)=3.73, p=$ .056]. However, there was an interaction between the effects of scopolamine and insulin $[F(5,128)=2.47, p<$ $.04]$. Simple main effects showed that the animals that received a combined injection of scopolamine $(0.6$ and $1.0 \mathrm{mg} / \mathrm{kg}$ ) and insulin made significantly more reinforced responses during the retention test than those that received scopolamine and saline $[F(1,128)=6.5$ and 6.96 , respectively, $p<.02]$. No such effect was observed in the groups that received either the lower doses of scopolamine $[0.1,0.2$, and $0.3 \mathrm{mg} / \mathrm{kg} ; F(1,128)=0.1,1.51$, and 0.62 , respectively] or only saline $[F(1,128)=0.427]$. These results show that insulin significantly attenuated the deleterious effect of high doses of scopolamine on the retention performance, whereas insulin alone did not produce any effect on the retention performance.

\section{DISCUSSION}

The present experiment shows that although insulin alone had no effect on memory per se, it did produce an attenuation of the amnesia produced by scopolamine. The lack of an action of posttraining insulin alone on memory is consistent with results from a previous report in which the effects of a wide range of doses of insulin (0.25$4 \mathrm{IU} / \mathrm{kg}$ ) on memory processes were examined (Messier et al., 1987). However, at least one study has shown a modest facilitatory action of insulin on memory processes (Santucci, Schroeder, \& Riccio, 1990), suggesting that insulin may interact with memory processes under certain experimental conditions. Insulin has also been shown to shift the dose-response curve of the facilitatory effect of glucose on memory (Messier et al., 1987).

Our prediction that insulin would increase the magnitude of scopolamine-induced amnesia was not supported by the present results. This prediction was based on two sets of data. The first set showed that increased glucose availability produces an attenuation of scopolamineinduced amnesia and can attenuate scopolamine effects on acetylcholine synthesis and release. The second set of data suggested that large doses of insulin could reduce acetylcholine content or turnover. We thus hypothesized that the ACh turnover reduction previously shown to be produced by insulin would lead to a potentiation of scopolamine-induced amnesia, because it would also accentuate the depletion of intraneuronal acetylcholine produced by scopolamine in the brain. This last action would have been the result of the reduction of acetyl-coA availability, following the presumed reduction of CNS glucose availability, produced by peripheral insulin injections. Contrary to our prediction, the data showed that insulin did not potentiate scopolamine amnesia, but did significantly attenuate the amnesia produced by posttraining injections of scopolamine $(0.6$ and $1.0 \mathrm{mg} / \mathrm{kg})$.

From the results of previous studies showing that fasting (Kuntscherova, 1972) or insulin injections (Gibson \& Blass, 1976) reduced brain ACh turnover or content, we had assumed that moderate doses of insulin would pro- 
duce a similar if somewhat milder effect. As discussed in the method section, the insulin dose of $0.8 \mathrm{IU} / \mathrm{kg}$ was the highest we could use without producing significant behavioral disruptions in our experimental conditions. On the other hand, Gibson (Gibson \& Blass, 1976) used much larger doses (125 IU) in fasted rats. It is quite likely that the insulin dose used in the present experiment did not produce the reduction in glucose levels sufficient to affect ACh synthesis or release. This hypothesis could very well account for an absence of insulin-induced effects on scopolamine amnesia. However, it is unlikely that mild hypoglycemia, as such, would lead to an attenuation of scopolamine-induced amnesia or would increase ACh synthesis to produce this attenuation. Alternatively, insulin could act to change the kinetics of glucose transport through the blood-brain barrier. However, this effect of insulin is small and does not appear to have significant functional consequences on glucose metabolism (Namba et al., 1987). The protective action of insulin raises the intriguing possibility that, in the present experiment, insulin may have had an action on the substrate of scopolamine-induced amnesia independently of its action on blood glucose.

Because insulin is released by peripheral glucose injections, it is also possible that glucose attenuation of scopolamine-induced amnesia is mediated by insulin release rather than by a direct action on brain ACh synthesis, as suggested by the various data presented in the introduction. However, at this time it is not clear how insulin would interact with neural substrates involved in memory processes to produce this action. One possible mechanism could involve CNS insulin receptors.

Insulin receptors are present in large numbers in different brain structures, including the entorhinal cortex, the subiculum, the amygdala, the lateral septum, and the hippocampal CA1 field (Unger, Livingston, \& Moss, 1991; Werther et al., 1987). All of these structures are implicated in one way or another with memory processing. Immunocytochemical detection of insulin receptors reveal their presence on the cell membranes of neurons; they are also localized on postsynaptic terminals (Unger et al., 1991). However, little is known about the function of neuronal insulin receptors. In vitro studies have shown that choline acetyltransferase activity was stimulated by insulin in cultured embryonic chicken retina neurons (Kyriakis, Hausman, \& Peterson, 1987). In preparations of hippocampal slices, insulin decreased the firing rate of pyramidal neurons, whereas in hypothalamic slices, insulin induced the release of both norepinephrine and dopamine (Palovick, Phillips, Kappy, \& Raizada, 1984; Sauter, Goldstein, Engel, \& Ueta, 1983).

These results are consistent with the hypothesis that insulin could attenuate the action of scopolamine through an action on its receptors in the CNS. For example, neuronal insulin receptors (Raizada et al., 1988) could directly modulate the muscarinic receptor response at the postreceptor level. These possibilities are only speculations at this time, because little is known about the functional role of neuronal insulin receptors. In the future, researchers will have to directly address the status of cholinergic neurons and cholinergic neurotransmission in the presence of various physiological levels of insulin.

The present results show that insulin can attenuate scopolamine amnesia. Previous results have shown that changes in glucose levels can modulate memory. This effect can be achieved either directly with glucose injections (Gold, 1991) or through the injection of glucose analogs such as 3-0-methyl-glucose and 2-deoxy-glucose (Messier \& White, 1987), or with substances that have a high affinity for the glucose transporter, such as phlorizin (Hall, Reilly, Cottrill, Stone, \& Gold, 1992). These animal studies are also supported by a growing number of human studies that have demonstrated a facilitative action of glucose on memory, particularly in older subjects (Craft et al., 1992; Parsons \& Gold, 1992a). Other lines of research have linked memory and cognitive deficits to $a b-$ normalities in glucose regulation in non-insulin-dependent diabetic subjects (Richardson, 1990), Alzheimer's patients (Harik \& Kalaria, 1991; Harik \& Lamanna, 1991; Hoyer, 1991; Hoyer, Nitsch, \& Oesterreich, 1991; Rapoport et al., 1991), or in patients suffering from inborn metabolic diseases (Blass \& Gibson, 1979). Taken together, these observations suggest the importance of glucose regulation, either in the brain or in the periphery, for learning and memory processes.

\section{REFERENCES}

Bartus, R. T., Dean, R. L., Beer, B., \& Lippa, A. S. (1982). The cholinergic hypothesis of geriatric memory dysfunction. Science, 217, 408-417.

Blass, J. P., \& Gibson, G. E. (1979). Carbohydrates and acetylcholine synthesis: Implications for cognitive disorders. In K. L. Davis \& P. A. Berger (Eds.), Brain acetylcholine and neuropsychiatric disease (pp. 215-236). New York: Plenum.

Brito, G. N. O., Davis, B. J., Stopp, L. C., \& Stanton, M. E. (1983). Memory and the septo-hippocampal cholinergic system in the rat. Psychopharmacology, 81, 315-320.

Burgel, P., \& RommelsPaCher, H. (1978). Changes in high affinity choline uptake in behavioral experiments. Life Sciences, 23, 2423-2428.

Craft, S., Zallen, G., \& BAKer, L. D. (1992). Glucose and memory in mild senile dementia of the Alzheimer type. Journal of Clinical \& Experimental Neuropsychology, 14, 253-267.

Destrade, C., Soumireu-Mourat, B., \& Cardo, B. (1973). Effects of post-trial hippocampal stimulation on acquisition of operant behavior in the mouse. Behavioral Biology, 8, 713-724.

DURKIN, T. (1989). Central cholinergic pathways and learning and memory processes: Presynaptic aspects. Comparative Biochemistry \& Physiology, 93A, 273-280.

Durkin, T. P., Messier, C., Boer, P. D., \& Westerink, B. H. C. (1992). Raised glucose levels enhance scopolamine-induced acetylcholine outflow from the hippocampus: An in vivo microdialysis study in the rat. Behavioural Brain Research, 49, 181-188.

FLOOD, J. F., \& CHERKIN, A. (1986). Scopolamine effects on memory retention in mice: A model of dementia? Behavioral \& Neural Biology, 45, 169-184.

GIBSON, G., \& BLASS, J. P. (1976). Impaired synthesis of acetylcholine in brain accompanying mild hypoxia and hypoglycemia. Journal of Neurochemistry, 27, 37-42.

Gibson, G. E., Jope, R., \& Blass, J. P. (1975). Reduced synthesis of acetylcholine accompanying impaired oxidation of pyruvic acid in rat brain slices. Biochemistry Journal, 148, 17-23. 
Gold, P. E. (1991). An integrated memory regulation system: From blood to brain. In R. C. A. Frederickson, J. L. McGaugh, \& D. L. Felten (Eds.), Peripheral signalling of the brain: Role in neuralimmune interactions, learning and memory (pp. 391-420). Toronto: Hogrefe \& Huber.

Gold, P. E., VoGt, J., \& Hall, J. L. (1986). Glucose effects on memory: Behavioral and pharmacological characteristics. Behavioral \& Neural Biology, 46, 145-155.

Gonder-Frederick, L., Hall, J. L., Vogt, J., Cox, D. J., Green, J., \& GoLD, P. E. (1987). Memory enhancement in elderly humans: Effect of glucose ingestion. Physiology \& Behavior, 41, 503-504.

Hall, J. L., Gonder-Frederick, L. A., Chewning, W. W., SilVEIRA, J., GoLD, P. E. (1989). Glucose enhancement of performance on memory tests in young and aged humans. Neuropsychologia, 27, 1129-1138.

Hall, J. L., Reilly, R. T., Cottrill, K. L., Stone, W. S., \& Gold, P. E. (1992). Phlorizin enhancement of memory in rats and mice. Pharmacology, Biochemistry \& Behavior, 41, 295-299.

HARIK, S. I., \& KALARIA, R. N. (1991). Blood-brain barrier abnormalities in Alzheimer's disease. Annals of the New York Academy of Sciences, 640, 47-52.

HaRIK, S. I., \& LamanNa, J. C. (1991). Altered glucose metabolism in microvessels from patients with Alzheimer's disease. Annals of Neurology, 29, 573.

HOYER, S. (1991). Abnormalities of glucose metabolism in Alzheimer's disease. Annals of the New York Academy of Sciences, 640, 53-58.

Hoyer, S., NitsCh, R., \& Oesterreich, K. (1991). Predominant abnormality in cerebral glucose utilization in late-onset dementia of the Alzheimer type: A cross-sectional comparison against advanced lateonset and incipient early-onset cases. Journal of Neural Transmission: Parkinson's Disease \& Dementia Section, 3, 1-14.

Jaffard, R., Galey, D., Micheau, J., \& Durkin, T. (1985). The cholinergic septo-hippocampal pathway and learning and memory. In B. E. Will, P. Schmitt, \& J. C. Dalrymple-Alford (Eds.), Brain plasticity, learning and memory (pp. 167-181). New York: Plenum.

KunTsCherova, J. (1972). Effect of short-term starvation and choline on the acetylcholine content of organs of albino rats. Physiologia Bohemoslovaca, 21, 655-660.

Kyriakis, J. M., Hausman, R. E., \& Peterson, S. W. (1987). Insulin stimulates choline acetyltransferase activity in cultured embryonic chicken retina neurons. Proceedings of the National Academy of Sciences, 84, 7463-7467.

LeE, M. K., Graham, S. N., \& Gold, P. E. (1988). Memory enhancement with posttraining intraventricular glucose injections in rats. $B e$ havioral Neuroscience, 102, 591-595.

long, J. M., Davis, B. J., Garofalo, P., Spangler, E. L., \& INGRAM, D. K. (1992). Complex maze performance in young and aged rats: Response to glucose treatment and relationship to blood insulin and glucose. Physiology \& Behavior, 51, 411-418.

Manning, C. A., Parsons, M. W., \& Gold, P. E. (1992). Anterograde and retrograde enhancement of 24-h memory by glucose in elderly humans. Behavioral \& Neural Biology, 58, 125-130.

Matthies, H., Rauca, C., \& LiebmanN, H. (1974). Changes in acetylcholine content of different brain regions of the rat during a learning experiment. Journal of Neurochemistry, 23, 1109-1113.

Means, L. W., \& Fernandez, T. J. (1992). Daily glucose injections facilitate performance of a win-stay water-escape working memory task in mice. Behavioral Neuroscience, 106, 345-350.

Messier, C., \& Destrade, C. (1988). Improvement of memory for an operant response by post-training glucose in mice. Behavioural Brain Research, 31, 185-191.

Messier, C., Durkin, T., Mrahet, O., \& Destrade, C. (1990). Memory-improving action of glucose: Indirect evidence for a facilitation of hippocampal acetylcholine synthesis. Behavioural Brain Research, 39, 135-143.

Messier, C. \& WhITE, N. M. (1984). Contingent and non-contingent actions of sucrose and saccharin reinforcers: Effects on taste preference and memory. Physiology \& Behavior, 32, 195-203.

Messier, C., \& WhITE, N. M. (1987). Memory improvement by glu- cose, fructose and two glucose analogs: A possible effect on peripheral glucose transport. Behavioral \& Neural Biology, 48, 104-127.

Namba, H., Lucignani, G., Nehlig, A., Patlak, C., Pettigrew, K., KenNedy, C., \& SoKolofF, L. (1987). Effects of insulin on hexose transport across blood-brain barrier in normoglycemia. American Journal of Physiology, 252, E299-E303.

Olton, D. S., Wible, C. G., \& Shapiro, M. L. (1986). Mnemonic theories of hippocampal function. Behavioral Neuroscience, 100, 852-855

Packard, M. G., \& White, N. M. (1990). Effect of posttraining injections of glucose on acquisition of two appetitive learning tasks. Psychobiology, 18, 282-286.

Palovick, R. A., Phillips, I. M., Kappy, M. S., \& Raizada, M. K. (1984). Insulin inhibits pyramidal neurons in hippocampal slices. Brain Research, 309, 187-191.

Parsons, M. W., \& Gold, P. E. (1992a). Glucose enhancement of memory in elderly humans: An inverted-U dose-response curve. Neurobiology of Aging, 13, 401-404.

Parsons, M. W., \& Gold, P. E. (1992b). Scopolamine-induced deficits in spontaneous alternation performance. Behavioral \& Neural Biology, 57, 90-92.

Quartermain, D., \& Leo, P. (1988). Strength of scopolamine-induced amnesia as a function of time between training and testing. Behavioral \& Neural Biology, 50, 300-310.

QUASTEL, J. H. (1978). Source of the acetyl group in acetylcholine. In D. J. Jenden (Ed.), Cholinergic mechanisms and psychopharmacology (pp. 411-430). New York: Plenum.

RAAIJMAKERS, W. (1982). High affinity choline uptake in hippocampal synaptosomes and learning in the rat. In C. Ajmone-Marsan \& H. Matthies (Eds.), Neuronal plasticity and memory formation (pp. 373-385). New York: Raven.

Raizada, M. K., Shemer, J., Judkins, J. H., Clarke, D. W., MASTERS, B. A., \& LERoIth, D. (1988). Insulin receptors in the brain: Structural and physiological characterization. Neurochemical Research, 13, 297-303.

RaPoport, S. I., HoRWITZ, B., Grady, C. L., HaXby, J. V., DeCARLI, C., \& SchapIRo, M. B. (1991). Abnormal brain glucose metabolism in Alzheimer's disease, as measured by positron emission tomography. Advances in Experimental Medicine \& Biology, 291, 231-248.

Rauca, C., Kammerer, E., \& Matthies, H. (1980). Choline uptake and permanent memory storage. Pharmacology, Biochemistry \& Behavior, 13, 21-25.

Richardson, J. T. E. (1990). Cognitive function in diabetes mellitus. Neuroscience \& Biobehavioral Reviews, 14, 385-388.

Ricny, J., TuceK, S., \& Novakova, J. (1992). Acetylcarnitine, carnitine and glucose diminish the effect of muscarinic antagonist quinuclidinyl benzilate on striatal acetylcholine content. Brain Research, 576, 215-219.

Rodriguez, W. A., Van Ausdle, L. R., Dhanens, K., \& MonDRAGON, A. N. (1993). Glucose modulates recently reactivated memories. Psychobiology, 21, 93-100.

RuSH, D. K. (1988). Scopolamine amnesia of passive avoidance: A deficit of information acquisition. Behavioral \& Neural Biology, 50, 255-274.

SANTuCCI, A. C., SChroeder, H., \& Riccio, D. C. (1990). Homeostatic disruption and memory: Effect of insulin administration in rats. Behavioral \& Neural Biology, 53, 321-333.

Sauter, A., Goldstein, M., Engel, J., \& Ueta, K. (1983). Effect of insulin on central catecholamines. Brain Research, 260, 330-333.

Stone, W. S., CotTrill, K. L., \& Gold, P. E. (1987). Glucose and epinephrine attenuation of scopolamine-induced increases in locomotor activity in mice. Neuroscience Research Communications, 1, 105-111.

Stone, W. S., Croul, C. E., \& Gold, P. E. (1988). Attenuation of scopolamine-induced amnesia in mice. Psychopharmacology, 96, $417-420$.

Stone, W. S., Rudd, R. J., \& Gold, P. E. (1990). Amphetamine, epinephrine, and glucose enhancement of memory retrieval. Psychobiology, 18, 227-230. 
Toumane, A., Durkin, T., Marighetto, A., Galey, D., \& JAFFARD, R. (1988). Differential hippocampal and cortical cholinergic activation during the acquisition, retention, reversal and extinction of a spatial discrimination in an 8-arm radial maze by mice. $B e$ havioural Brain Research, 30, 225-234.

Toumane, A., Durkin, T., Marighetto, A., \& JafFard, R. (1989). The durations of hippocampal and cortical cholinergic activation induced by spatial discrimination testing of mice in an eight-arm radial maze decrease as a function of acquisition. Behavioral \& Neural Biology, 52, 279-284.

TUCEK, S. (1983). Acetylcoenzyme A and the synthesis of acetylcholine in neurones: Review of recent progress. General Physiology \& Biophysics, 2, 313-324.

TUCEK, S. (1985). Regulation of acetylcholine synthesis in the brain. Journal of Neurochemistry, 44, 11-24.

TuCEK, S., RicnY, J., \& Dolezal, V. (1982). Acetylcoenzyme A and the control of the synthesis of acetylcholine in the brain. Acta Neurobiologica Experimentalis, 42, 59-68.
UNGer, J. W., Livingston, J. N., \& Moss, A. M. (1991). Insulin receptors in the central nervous system: Localization, signalling mechanisms and functional aspects. Progress in Neurobiology, 36, 343-362. Werther, G. A., Hogg, A., Oldfield, B. J., McKinley, M. J., FigDOR, R., AlleN, A. M., \& MendelsohN, F. A. O. (1987). Localization and characterization of insulin receptors in rat brain and pituitary gland using in vitro autoradiography and computerized densitometry. Endocrinology, 121, 1562-1570.

White, N. M. (1991). Peripheral and central memory enhancing actions of glucose. In R. C. A. Frederickson, J. L. McGaugh, \& D. L. Felten (Eds.), Peripheral signalling of the brain: Role in neuralimmune interactions, learning and memory (pp. 421-443). Toronto: Hogrefe \& Huber.

(Manuscript received March 23, 1993; revision accepted for publication October 4, 1993.) 